of the temporarily displaced population of the Chechen Republic, including 480 children, were examined. In $11.3 \%$ cases some psychological diseases were revealed among the adult population: manic-depressive syndrome, schizophrenia, epilepsy, and psychoorganic syndrome. In $81.5 \%$ of cases, non-psychotic disorders were diagnosed, which were demonstrated by neurotic character and behavioral disorders.

Considerable place in the structure of nonpsychotic forms of psychic disorders was taken by lasting hypothymic situational reactions-anxiety and dysphoria-caused by situations. Specialists of psychological-psychic teams used the correction program for nonpsychotic forms of disorders (developed by the authors) among persons, being examined. This program included program of pharmacological support (three-cycle antidepressants, MAO inhibitors, etc), transpersonal psychotherapy, information-wave technologies (microwave resonance therapy, mesodyencephaly modulation, etc) that allowed them to obtain corrective effects in $87 \%$. Patients with psychic diseases were sent for treatment into specialized medical institutions in cities of the Russian Federation (Krasnodar, Rostov, Vladicavkaz, etc.).

The system presented for rendering psychological-psychiatric assistance to the population was very effective, since it revealed the main forms of psychic disorders in the early stages. Special programs of treatment allowed correction in $87 \%$ of the cases. This system may be proposed for use in other countries in local conflicts and humanitarian disasters.

Key words: complex human emergencies; displaced populations; pharmacological support; psychological disorders; psychotherapy; recognition;

E-mail: rcdm.org@g23.relcom.ru

Prehosp Disast Med 2001;16(2):57.

\section{Deployment of French Military Field Hospital Following the 1999 Earthquake in Turkey M. Puidupin; ${ }^{1}$ C.H. Rapp, ${ }^{2}$ G. Fevre, ${ }^{2}$ B. Tramond, ${ }^{2}$ T.H. Lonjon; ${ }^{1}$ P. Bocaccio ${ }^{1}$}

1. 7th Surgical Airborne Team 1er Toulouse Armees, FRANCE

2. Military Hospital Begin, Armees, FRANCE

On 22 August 1999, France sent a military field hospital to relieve the rescue clearing team of the Security Service and to complete the first aid organization to the victims of the earthquake that occurred in Turkey. This hospital was deployed under tents near the disaster-stricken local hospital in AKYAZI (200 km from Istanbul). It is important to restore the confidence of a disaster-stricken population that suffered from a recurrence of an earthquake. The rules of the action are: (1) reinforcement of the local medical organization that sorts the patients in order to send them to our hospital, (2) total autonomy of the hospital, and (3) close collaboration with the Turkish authorities to adapt the medical activity to the needs of the population.

During 24 days, the activities included 143 surgeries (46\% of pediatric surgeries), 1,491 med surgeries, 1,262 radiology procedures, and 151 patients hospitalized.

Key words: deployment; earthquake; field hospital; rules; triage

Prebosp Disast Med 2001;16(2):s57.

\section{Pediatric Anesthesia by Military Field Hospital in Disaster Situation \\ M. Puidupin; $;^{1}$ G. Fevre,, 2 A. Puidupin, ${ }^{3}$ D. Petit; ${ }^{4}$ T.H. Lonjon; $^{1}$ P. Bocaccio ${ }^{1}$ \\ 1. 7th Surgical Airborne Team 1er Toulouse, Armees, FRANCE \\ 2. Military Hospital Begin, Armees, FRANCE \\ 3. Military Hospital Desgenettes, Armees, FRANCE \\ 4. Military Hospital Sainte Anne Toulon Naval. FRANCE}

Military surgical teams also are employed in disaster situations. During 1999, they were deployed in a humanitarian mission in Turkey for earthquake victims, in East Timor for refugees, and in Chad for helping poor people beside the military mission. In these countries, the population is very young and surgical teams have performed many pediatric surgeries, mainly in emergencies: 158 children, $22 \%$ of all surgeries in the three missions and $46 \%$ in Turkey.

Many types of surgery were performed, and in these emergency and disaster situations, the anesthetic procedure must be very simple. Loco-regional anesthesia is a good way to easily manage pediatric analgesia.

Key words: anesthesia; children; earthquake; military; refugees; surgery; teams

Prehosp Disast Med 2001;16(2):s57.

\section{Medical Radio Network Contribution for Medevac during Military Operations Alain Puidupin HIAD Desgenettes, Lyon, FRANCE}

Due to the impossibility of medical coordination, medical assistance in military operations is based upon a convoy of ambulances for medical evacuation, and upon mandatory stages of treatment or dispatching. Medical reports are written on field medical cards (NATO format), and reviewed or transcribed at each and every stage of medical care. Emergency categorization is made at the surgical clearing center, after first level of evacuation and the injured having been through the battalion first aid post. During the Gulf War, casualties were taken directly into the charge of medical teams on the battlefield. In Sarajevo, during peacekeeping operations, in order to reduce the waiting period before surgical treatment, simplified procedures were developed thanks to the use of operational radio networks and special medical messages. With the use of medical radio networks, regiment or battalion medical doctors can sort casualties, which could be dispatched directly to the specified field hospitals that are able to treat their respective injuries. Medical examination data also could be collected through a computer software application. These 